Warren, N., Elastic constants versus porosity for a highly porous ceramic, perlite, J. Geophys. Res., 74, 713, 1969.

Wong, C., and D. E. Schuele, Pressure and temperature deriv- atives of the elastic constants of $\mathrm{CaF}_{2}$ and $\mathrm{BaF}_{2}, J$. Phys. Chem. Solids, 29, 1309, 1968

\section{Static and Dynamic Compression of Earth Materials}

\author{
Thomas J. Ahrens and Taro Takahashi
}

The triennium, 1967-1970, has been a period of marked increase in acquisition of pressure-volume data for minerals, rocks, and compounds of geophysical interest. A wide assortment of data has been obtained by the conventional dilatometric techniques as well as by the more recently developed X-ray diffraction and shock-wave techniques. Highlights of progress during the last 3 years include hydrostatic compression measurements for Apollo 11 lunar samples [Stephens and Lilley, 1970; Schreiber et al., 1970], static compression measurements of the spinel phase of $(\mathrm{Mg}, \mathrm{Fe})_{2} \mathrm{SiO}_{4}$ solid solutions, which are likely constituents of the transition zone of the earth's mantle [Mao et al., 1969], and Hugoniot data for high-pressure phases of ferromagnesian silicates, which may represent the constituents of the lower mantle [McQueen et al., 1967b].

\section{Static Compression}

Isothermal static compression of minerals (including elements) has been conducted by two different techniques: the X-ray diffraction methods for powdered specimens, and the dilatometric methods for polycrystalline aggregates and single-crystal specimens. The X-ray diffraction methods have been used for a study of milligram-size powdered crystalline samples, and the dilatometric methods have been used exclusively for static compression studies of rocks and aggregates.

A variety of designs for X-ray diffraction highpressure cells are currently in use in the United States. They include diamond-anvil cells [Bassett et al., 1967; Weir et al., 1969], tungsten carbide Bridgman anvil cells [Jamieson, 1965; McWhan and Bond, 1964], supported tungsten carbide anvil cells [Perez-Albuerene et al., 1964; Freud and Sclar, 1969; Freud and LaMori, 1969l, and a tetrahedral tungsten carbide cell [Barnett and Hall, 1964]. Recent advances in X-ray techniques are summarized by $M c$ Whan [1969]. Accuracies of $\pm 0.1 \%$ in

Thomas J. Ahrens is with the California Institute of Technology, Seismological Laboratory, Pasadena 91109. Taro Takahashi was with the Seismological Laboratory, California Institute of Technology, when this report was prepared: he is now at the Department of Earth and Environmental Sciences, Queens College, CUNY, New York 11367. lattice parameter and, hence, of $\pm 0.3 \%$ in volume, under high pressures, have been attained by these methods.

The pressures imposed on powdered specimens in these high-pressure cells are determined by using 'pressure markers' or internal pressure standards such as $\mathrm{NaCl}$ or $\mathrm{Al}$ for which the pressure-volume $(P-V)$ isotherm are assumed to be known. Drickamer et al. [1966] use $\mathrm{Ag}, \mathrm{Al}, \mathrm{Mo}, \mathrm{Nb}, \mathrm{Pd}$, or $\mathrm{V}$ as a standard. The isotherms for these materials were obtained from the reduced Hugoniot data of Rice et al. [1958]. Other investigators prefer $\mathrm{NaCl}$, since its equation of state has been extensively studied by shock, static, and ultrasonic methods. The pressure indicated by the lattice parameters of the internal pressure standard, which is mechanically mixed with the sample, is often assumed to be equal to the pressure applied on each grain of the sample. In certain cases, e.g., $\mathrm{NaCl}$ and $\mathrm{Nb}$ metal powder compressed between Bridgman-type tungsten carbide anvils, Jamieson and Olinger $[1968 a, b]$ have shown that this assumption is not always valid. Hence, care must be exercised to assure that complete flowage of the pressure medium around each sample grain has occurred when performing $\mathrm{X}$-ray experiments.

The $25^{\circ} \mathrm{C}$ isotherm of $\mathrm{NaCl}$ has been calculated up to several hundred kilobars by Decker [1965, 1966] using the Mie-Grüneisen equation and the Born-Mayer interionic potential, by Perez-Albuerne and Drickamer [1965] and Weaver et al. [1968] using the Hildebrand equation and the Born-Mayer type interionic potential, and by Thomsen [1970] using a fourth-order anharmonic equation derived from the finite strain theory. This isotherm has also been calculated by Christian [1957] and Fritz et al. [1968] from Hugoniot data for $\mathrm{NaCl}$. (The Hugoniot data of Christian and Fritz et al. agree with those of Al'tshuler et al. [1961] and Hauver and Melani [1970].) With the exception of Decker's isotherm, the theoretical $25^{\circ} \mathrm{C}$ isotherms, the isotherms of Perez-Albuerne et al. and Weaver et al., and those reduced from Hugoniot data agree to within about $10 \mathrm{~kb}$ at $300 \mathrm{~kb}$. Decker $[1965,1966]$ used a bulk modulus value of $234.2 \mathrm{~kb}\left(25^{\circ} \mathrm{C}\right)$ instead of the current best value of $237.5 \pm 1.5 \mathrm{~kb}$. If his equation is corrected for the initial bulk modulus, it yields $P-V$ relations that are in agreement with the others. The new isotherms for $\mathrm{NaCl}$ also agree with the $100-\mathrm{kb}$ static compression data of Bridgman [1945].

The $P \cdot V$ relationship for $\mathrm{NaCl}$ can also be compared with the fixed points in the pressure scale established by using such first-order phase transformations as those in $\mathrm{Bi}, \mathrm{TI}$, and $\mathrm{Ba}$. The phase transformation pressures for those materials have been accurately determined by Kennedy and LaMori [1962], Heydemann [1967], Haygarth et al. [1967], and Haygarth et al. [1968]; the volumes of $\mathrm{NaCl}$ at these transformation pressures have been determined by Jeffery et al. [1966] up to $80 \mathrm{~kb}$. 
Weaver et al. [1968] have shown that the fixed points pressure scale agrees with the $\mathrm{NaCl}$ isotherm within the experimental and calculational uncertainties. The consistency of the pressure scale was tested by determining the isotherm for $\mathrm{MgO}$ with X-ray techniques by $\mathrm{McWhan}$ [1967] up to $120 \mathrm{~kb}$ and by Weaver et al. [1968] up to $280 \mathrm{~kb}$. Since $\mathrm{MgO}$ compresses to a $V / V_{0}$ value of 0.87 at $300 \mathrm{~kb}$, a reliable compression value for $\mathrm{MgO}$ can be computed with the Birch-Murnaghan or Murnaghan equations using the bulk modulus $K_{0}$ and $K_{0}{ }^{\prime}$ $\left(=(\partial K / \partial P)_{T}\right.$ evaluated at zero pressure $)$ measured ultrasonically in single crystals [Anderson and $A n$ dreatch, 1966; Spetzler, 1970]. The $\mathrm{NaCl}$ isotherm calculated by the above investigators is consistent with the $\mathrm{MgO}$ isotherm within the experimental uncertainties up to $280 \mathrm{~kb}$, the highest pressure tested. On the basis of the experimental and the theoretical evidence, it is not yet possible to determine which of the currently available isotherms for $\mathrm{NaCl}$ is most reliable. Thus, at present, the $\mathrm{NaCl}$ pressure scale for room temperature appears to be known within $\pm 3 \%$ in pressure up to 300 $\mathrm{kb}$. Above $300 \mathrm{~kb} \mathrm{NaCl}$ transforms to a high-pressure polymorph having a simple cubic $\mathrm{B} 2$, or $\mathrm{CsCl}$ structure [Bassett et al., 1968]. More refined measurements of the elastic properties of $\mathrm{NaCl}$, as well as improvement in the theories on the effect of pressure and temperature on the Grüneisen parameter, are necessary for further improvement of the pressure scale. Recent progress in high-pressure standards and calibrations are reviewed by Decker et al. [1969].

The Murnaghan trajectory for Au calculated by using the $K_{0}$ and $K_{0}$ 'values of Barsch and Chang [1967] was used as a standard in dilatometric compression measurements by Vaidya and Kennedy [1970] and others. Grover [1970] compared the isothermal compression data of Vaidya and Kennedy [1970] for eighteen metals to $45 \mathrm{~kb}$ with the $25^{\circ} \mathrm{C}$ isotherms reduced from the available shock Hugoniot data. He concluded that the static compression data of Vaidya and Kennedy, the sound velocity data, and the shock Hugoniot data are mutually consistent within $2 \%$ in pressure up to $45 \mathrm{~kb}$. The $P \cdot V$ relationships for $\mathrm{Au}$ and $\mathrm{NaCl}$, which are used as the standdards for static compression measurements, appear to be consistent with those determined from the shock and ultrasonic data.

A symposium on measurements of high-pressure environment was held in October 1968 under the sponsorship of the U.S. National Bureau of Standards and the Geophysical Laboratory, Carnegie Institution of Washington. The highlights of this symposium are briefly described by Lloyd et al. [1969], and the complete proceedings are currently in press.

McWhan [1967] determined the effect of pressure on the lattice parameters of $\alpha$-quartz at room temperature up to $150 \mathrm{~kb}$, using a Bridgman carbide anvil highpressure cell and the Guinier focusing geometry for X-ray diffraction. Bassett and Barnett [1970] measured the effect of pressure on the lattice parameters of synthetic coesite and stishovite up to $85 \mathrm{~kb}$, using a tetrahedral press X-ray diffraction apparatus. Liu et al. [1969] measured the effect for synthetic stishovite up to $220 \mathrm{~kb}$, using a diamond-anvil press and the DebyeScherrer X-ray diffraction geometry.

Mao et al. [1969] studied the effect of pressure on the lattice parameter of wüstite $\left(\mathrm{Fe}_{0.924} \mathrm{O}\right)$, the spinel $(\gamma)$ phase of $\mathrm{Fe}_{2} \mathrm{SiO}_{4}, \quad\left(\mathrm{Fe}_{1.8} \mathrm{Mg}_{0.2}\right) \mathrm{SiO}_{4}$, and $\left(\mathrm{Fe}_{1.6} \mathrm{Mg}_{0.4}\right) \mathrm{SiO}_{4}$ up to $255 \mathrm{~kb}$ at room temperature using a diamond anvil X-ray diffraction camera [Bassett et al., 1967]. The bulk modulus value of $2.0 \pm 0.1 \mathrm{Mb}$ calculated for these three spinels $\left(\gamma(\mathrm{Fe}, \mathrm{Mg})_{2} \mathrm{SiO}_{4}\right)$ is consistent with the recent ultrasonic measurements by Mizutani et al. [1970]. The spinel phase of $\mathrm{Ni}_{2} \mathrm{SiO}_{4}$ was also studied by Mao et al. [1970] up to $300 \mathrm{~kb}$, and a bulk modulus value of $2.14 \pm 0.07 \mathrm{Mb}$ was reported.

Solid solutions of almandite $\left(\mathrm{Fe}_{3} \mathrm{Al}_{2} \mathrm{Si}_{3} \mathrm{O}_{12}\right)$-pyrope $\left(\mathrm{Mg}_{3} \mathrm{Al}_{2} \mathrm{Si}_{3} \mathrm{O}_{12}\right)$ were investigated by Takahashi and Liu [1970] up to $328 \mathrm{~kb}$ at room temperature, using a diamond anvil X-ray diffraction camera. A systematic increase in the bulk modulus with increasing $\mathrm{Mg}$ content was observed and a thermodynamic relationship between the bulk modulus and chemical composition was reported.

Mao et al. [1967] studied the compression of pure iron $\mathrm{up}$ to $300 \mathrm{~kb}$ at room temperature, using a diamond anvil X-ray diffraction camera. The volume change associated with the bcc-hcp phase transformation was determined to be $-0.34 \pm 0.01 \mathrm{~cm}^{3} / \mathrm{mole}$. This change is nearly twice as large as reported on the basis of the earlier Hugoniot data. The bulk modulus for the high-pressure hcp phase was experimentally indistinguishable from that of the low-pressure bcc phase. Silberman [1967] studied the effect of pressure on $\mathrm{Fe}-7.2 \% \mathrm{Si}$ alloy and $\mathrm{FeSi}_{3}$ up to $290 \mathrm{~kb}$ at room temperature, and Takahashi et al. [1968] studied the effect of pressure on $\mathrm{Fe}-5 \% \mathrm{Ni}$ and $\mathrm{Fe}-10 \% \mathrm{Ni}$ alloys up to $308 \mathrm{~kb}$ at room temperature. The effect of pressure on the bcc-hcp phase transformation in iron alloys, and the effect of the alloying elements on the bulk moduli, in both structures are discussed.

Drickamer and his associates have conducted an extensive survey of the effect of pressure up to $300 \mathrm{~kb}$ at room temperature on the lattice parameters of numerous compounds, using a supported carbide anvil high-pressure cell and Debye-Scherrer geometry [Perez-Albuerne et al., 1964]. The materials of geophysical interest studied by Drickamer and his associates include $\mathrm{Fe}_{1-\mathrm{x}} \mathrm{O}, \mathrm{SnO}_{2}$, $\mathrm{MnO}_{2}, \mathrm{TiO}_{2}, \mathrm{MnS}$, and $\mathrm{FeS}_{2}$ [Clendenen and Drickamer, 1966a], $\alpha \mathrm{Fe}_{2} \mathrm{O}_{3}, \mathrm{Cr}_{2} \mathrm{O}_{3}$ [Lewis and Drickamer, 1966], $\mathrm{Al}_{2} \mathrm{O}_{3}$ [Hart and Drickamer, 1965], $\mathrm{CaO}, \mathrm{MgO}$ [PerezAlbuerne and Drickamer, 1965], diamond, graphite [Lynch and Drickamer, 1966], $\mathrm{Fe}-8 \% \mathrm{Si}$, and $\mathrm{Fe}_{3} \mathrm{Si}$ [Clendenen and Drickamer, 1966b]. The results of the studies by Drickamer and his associates are summarized in Drickamer et al. [ 1966].

The effect of pressure on the lattice parameters of the $\alpha \mathrm{PbO}_{2}$ phase of $\mathrm{TiO}_{2}$ was investigated by Jamieson and Olinger $[1968 a, b]$ up to $200 \mathrm{~kb}$ at room temperature, using a Bridgman anvil cell and Debye-Scherrer X-ray diffraction geometry. An increase of the dimension of the unit cell along the $c$ axis with pressure was observed up to $120 \mathrm{~kb}$, whereas little change was observed in the $a$ axis dimension. 
Barnett et al. [1969] investigated the effect of pressure on $\mathrm{NaNO}_{3}$, using a tetrahedral anvil X-ray diffraction apparatus [Barnett and Hall, 1964] and determined the linear and bulk compressibilities up to $85 \mathrm{~kb}$. They observed anomalous line intensity changes near $45 \mathrm{~kb}$. This change was attributed to a transition from $R \overrightarrow{3} c$ space group to $R 3 c$ with no measurable discontinuity in volume. They infer that this higherorder transition represents rotation of the nitrate groups in alternate layers along the trigonal axis in opposite directions with increasing pressure. At high pressures the nitrogen positions are no longer planar with the oxygen atoms. Although the analogous change in atomic arrangements has not been experimentally demonstrated in silicate minerals, it is likely to occur with compression. If this type of rotation occurs, it would greatly affect the bulk modulus of silicates at high pressures.

Brace et al. [1969] determined the isothermal compressibility of kyanite, andalusite, and sillimanite by using a strain gage method [Brace, 1964] in a hydrostatic medium up to $10 \mathrm{~kb}$ and a solid medium piston-cylinder apparatus [LaMori, 1967] up to $40 \mathrm{~kb}$. The specimens studied were all hot pressed aggregates of (1:1) silicate/Cu or silicate/Pb mixtures. The compressibility values of the silicate specimens were obtained by subtracting the effect of the $\mathrm{Cu}$ or $\mathrm{Pb}$ matrix from the bulk compression for the mixture. They obtained a compressibility value of $0.77 \pm 0.04 \mathrm{Mb}^{-1}$ for all three materials at 1 bar and $25^{\circ} \mathrm{C}$ and could not detect the significant differences between these minerals.

Vaidya and Kennedy [1970] measured the effect of pressure on the volume of eighteen metals up to $45 \mathrm{~kb}$ at room temperature, using a piston-cylinder apparatus and $\mathrm{Au}$ as the standard. A precision of 0.0005 in $V / V_{0}$ for less compressible materials and of 0.0015 in $V / V_{0}$ for more compressible materials were achieved. Differences of up to $10 \%$ between their initial compressibility values and the values obtained by Bridgman [1940,1949] were found.

LaMori [1967] obtained static compression data for twenty rocks and minerals up to $36 \mathrm{~kb}$ in a temperature range of 22 to $450^{\circ} \mathrm{C}$ using a piston-cylinder apparatus with $\mathrm{Au}$ or $\mathrm{Pb}$ as the pressure medium. The results of these experiments give significantly lower compressibilities than were obtained by means of other experimental methods, such as the pulse-echo ultrasonic method up to $10 \mathrm{~kb}$. Such differences were attributed to the existence of pores in specimens at $10 \mathrm{~kb}$.

Stephens and Lilley [1968] have measured the static compression of Apollo 11 lunar crystalline rock, microbreccia, and dust specimens up to $40 \mathrm{~kb}$, using a piston-cylinder apparatus. They found that the intrinsic compressibility for the lunar dust is about $1.28 \mathrm{Mb}^{-1}$ and is similar to that for quartz and feldspar. Schreiber et al. [1970] investigated static compression behavior for a vesicular fine-grained crystalline rock collected on the Apollo 11 mission, using a hydrostatic apparatus [Brace, 1965] to $6 \mathrm{~kb}$. They found that the compressibility value for this rock specimen, $1.98 \mathrm{Mb}^{-1}$ at $5 \mathrm{~kb}$, is closer to acidic rocks than to basic rocks.

\section{Dynamic Compression}

In the area of shock compression, notable advances in the use of high-performance light gas, compressed gas, and propellant gun technology to launch shock generating flyer plates, at speeds that are difficult to achieve with high explosives (below $2 \mathrm{~km} / \mathrm{sec}$ and above 5 $\mathrm{km} / \mathrm{sec}$ ), has taken place [Jones et al., 1966; Linde and Schmidt, 1966; Lower and Ahrens, 1969; Morgan, 1969; and Fowles et al., 1970\}.

New Hugoniot data for a series of crustal and possible mantle type rocks (granite, diabase, dunite, eclogite, and bronzitite), monomineralic feldspar rocks, and a series of oxides and mixed oxides, have been reported to pressures in excess of $1 \mathrm{Mb}$ by McQueen and co-workers [McQueen and Marsh, 1966; McQueen et al., 1967b]. Hugoniot data for feldspars, granite, basalt, sandstone, and limestone and rutile are also reported in Ahrens et al. [1969a, b], Shipman [1969], Jones et al. [1968], McQueen et al. [1967a], and Linde and DeCarli [1969]. All but the data for four oxides, $\mathrm{Al}_{2} \mathrm{O}_{3}, \mathrm{MgO}, \mathrm{SnO}_{2}$, and $\mathrm{MnO}_{2}$, of the more than twenty silicate rocks, silicate minerals and oxides, and mixed oxide compounds tested show convincing evidence for shockinduced transitions to one or more denser phases or phase assemblages. Typically, the silicates display three distinct regimes along the Hugoniot: a low-pressure regime in which the Hugoniot represents states in the untransformed material and in which correlations with low-pressure ultrasonic data are possible; a mixed phase regime representing shock states that comprise a mixture of initial and transformed (high-pressure phase) minerals; and a high-pressure regime characterizing the equation of state usually of a denser high-pressure phase or phases.

The Hugoniot data in the high-pressure regime for Twin Sisters and hortonolite dunites [McQueen et al., $1967 \mathrm{~b}$, which at ambient pressure are largely composed of olivines with the compositions $\left(\mathrm{Mg}_{0.88}\right.$, $\left.\mathrm{Fe}_{0.12}\right)_{2} \mathrm{SiO}_{4}$ and $\left(\mathrm{Mg}_{0.44}, \mathrm{Fe}_{0.56}\right)_{2} \mathrm{SiO}_{4}$ [MaO et al., 1970 ], are of special significance to the study of the earth's interior. From the high-pressure data for these dunites $M c Q u e e n$ et al. [1967b] constructed metastable Hugoniots that bracketed the seismologically determined density-depth profiles in the lower mantle. This and an earlier correlation of the densities of the high-pressure oxide and silicate shock data with the density of the lower mantle by Birch [1964] have motivated intensive analytic study of these data.

Because the high-pressure phase Hugoniot data are available, in most cases in the range of 400 to over 1000 $\mathrm{kb}$, and hence, display substantial compressions, the use of at least a third-order equation of state relating Helmholtz free-energy and volume, centered at ambient pressure, is appropriate. To construct such an isothermal or isentropic equation of state, a minimum required set of three parameters would be the zero pressure density $\rho_{0}$ and the appropriate bulk modulus $K_{0}$ at constant entropy or temperature, and the pressure derivative of $K, K_{0}{ }^{\prime}$. With the usual availability of only 4 to 15 , or so, data points, and with the experimental scatter taken into account, the data set is not, in general, capable of 
independently yielding three parameters with acceptable uncertainties. (Of the class of silicates and oxides that undergo a shock-induced phase change, only for $\mathrm{SiO}_{2}$ (stishovite) are the zero pressure density and other thermodynamic properties measured.) Additional constraints to the equation of state of the high-pressure phases, relating the zero pressure bulk modulus $K_{0}$ and $\rho_{0}$ of the form

$$
K_{0}=a \rho_{0}{ }^{1 / 2}+b \rho_{0}^{3 / 2}
$$

and

$$
K_{0}=\rho_{0}^{1+1 / n} \cdot(A \bar{M})^{1 / n}
$$

have been proposed by Wang [1967] and Anderson and Kanamori [1968]. Here $a, b, n$, and $A$ are empirical parameters. The first expression is similar to Birch's [1961] linear relation between compressional-wave velocity and density at constant mean atomic weight $(\bar{M})$. The second, the seismic equation of state, SEOS, was proposed by Anderson [1967]. Both formulas fit a considerable body of ultrasonic data with similar variances. The first equation has the advantages that a similar form of the equation can also predict shear velocities fairly well; the second has the advantage that it explicitly treats the effect of changing mean atomic weight. Initially, Wang [1967], using the first equation, fit the shock data of McQueen and his co-workers by assuming a linear shock velocity-particle velocity type equation of state [McQueen et al, , 1970] and neglecting transitional energy and thermal effects. He concluded that the bronzitites transformed to stishovite plus a spinel phase and the dunites transformed to spinel structure. Later, taking into account shock heating but not transitional energies, Wang $[1968 a, b]$ again analyzed the shock data and concluded that on comparison with seismic results that the Twin Sisters dunite had slightly less $\mathrm{Fe}^{+*}$ than the rocks of the lower mantle. In the analysis of Anderson and Kanamori [1968], following $M c Q$ ueen et al. [1963], a series of metastable Hugoniots were constructed by using the BirchMurnaghan form for the equation of state and the SEOS to constrain the zero pressure densities. Revised separate values for $A$ and $n$ parameters appropriate for application to different mineral classes have recently been proposed by Anderson [1969]. Later analysis by Ahrens et al. [1969a] employed a similar approach, but the $\rho_{0}-K_{0}$ constraint was applied to the calculated highpressure phase isentrope and phase transition energies were separately estimated from thermochemical data. They inferred transformations to the following probable crystal structures (on the basis of the calculated zero pressure densities, the densities of silicates and of analog compound phases quenched from high pressure, and from crystal-chemical arguments): $\mathrm{MgAl}_{2} \mathrm{O}_{4}$ (spinel) to calcium ferrite structure, feldspars to hollandite structure, olivines to strontium plumbate structure, pyroxenes to ilmenite structure, kyanite, silliaminite, and andalusite to corundum plus stishovite, $\alpha \mathrm{Fe}_{2} \mathrm{O}_{3}$ (hematite) to the perovskite structure, and
$\mathrm{TiO}_{2}$ (rutile) to fluorite structure. Linde and DeCarli [1969] have considered the transformation of $\mathrm{TiO}_{2}$ to fluorite structure in detail and conclude that the density of $\mathrm{TiO}_{2}$ in the fluorite structure $\left(\sim 4.1 \mathrm{~g} / \mathrm{cm}^{3}\right)$ would be much lower density than the values obtained by McQueen et al. [1967a] $\left(5.65 \mathrm{~g} / \mathrm{cm}^{3}\right)$ and Ahrens et al. $[1969 a]\left(5.71 \mathrm{~g} / \mathrm{cm}^{3}\right)$.

To reduce Hugoniot data to other forms of the equation of state such as isotherms, isentropes, or, for phase changes, metastable Hugoniots, knowledge of the Grüneisen parameter, $\gamma=V(\partial P / \partial E) V$, and its variation with volume, and possibly internal energy $(E)$, is required. For cubic metals at temperatures below those at which electronic specific heat must be taken into account (e.g., $10,000^{\circ} \mathrm{K}$ ), and above the lattice Debye temperature, the formalism developed by Pastine and Forbes [1968] can be applied. Their development permits calculation of $\gamma$ as a function of $V$, directly from the Hugoniot data and supplementary data on specific heat, thermal expansion, and elastic constants (and derivatives of elastic constants with pressure). Where minerals do not undergo phase changes, the Hugoniot data may also be reduced by calculating the initial Grüneisen ratio from thermochemical data and determining its initial variation with compression from the thermodynamic formulas given by Bassett et al. [1968]. The results obtained by Wang [1968], Ahrens et al. [1969a], Carter et al. [1968], and Grover [1970] demonstrate that, where a phase change does not occur, the variations in the equation of state obtained from different assumptions regarding how $\gamma$ decreases with volume, are minor. Anderson [1968] has compared the variation of $\gamma$ obtained from several theories. Where there is a shock-induced phase change in a mineral, with the exception of stishovite [Ahrens et al., 1970], no explicit data, or relevant theory, giving the Grüneisen ratio of the high-pressure phase now exist. Various workers have employed the Slater [Anderson and Kanamori, 1968], Dugdale-McDonald [Ahrens et al., $1969 a$ ], and $\gamma / \mathrm{V}=$ constant [McQueen et al., 1967b Wang, 1968] assumptions. Knopoff and Shapiro [1969] have recently summarized the difficulties in each of these approaches. One promising, although experimentally difficult, technique for obtaining Grüneisen ratio data it high pressure is the application of Hugoniot curves for material centered at different initial porosities. Analysis of such data have been made for porous $\mathrm{MgO}$ [Carter et al., 1968] and initially porous $\alpha$ quartz in the stishovite regime [Ahrens et al., 1970].

Recently, some measurements of isentropes, centered at high pressure, i.e., adiabatic release curves, have been performed by novel shock-wave techniques. Such data are useful in porous rocks, such as in tuff [Lysne, 1970] and weathered tonolite [Petersen, 1970]. Release isentropes in such crystalline materials as plagioclase [Ahrens et al., 1969b] and quartz [Ahrens and Rosenberg, 1968] have also been reported. Another area of recent activity has been the study of dynamic yielding under shock compression. A host of interesting and challenging problems remain in this, $<100-\mathrm{kb}$ regime. Data for various oxides and silicates have been reported 
by Ahrens et al. [1968], Jones and Froula [1969], and Ahrens and Linde [1968].

\section{Acknowledgments}

This paper is Contribution 1947 of the Division of Geological Sciences, California Institute of Technology, Pasadena, California 91109 . The work was supported by DASA 01-70-C-0021.

\section{REFERENCES}

Ahrens, T. J., and R. L. Linde, Response of brittle solids to shock compression, in Behavior of Dense Media under High Dynamic Pressure, IUTAM, pp. 325-336, Gordon and Breach, New York, 1968.

Ahrens, T. J., and J. T. Rosenberg, Shock metamorphism: Experiments on quartz and plagioclase, in Shock Metamorphism of Natural Materials, edited by B. M. French and N. M. Short, Mono Press, Baltimore, Md., 1968.

Ahrens, T. J., W. H. Gust, and E. B. Royce, Material strength effect in the shock compression of alumina, J. Appl. Phys., 39 4610-4616, 1968.

Ahrens, T. J., D. L. Anderson, and A. E. Ringwood, Equation of state and crystal structure of high pressure phases of shocked silicates and oxides, Rev. Geophys., 7, 667-707, 1969a.

Ahrens, T. J., C. F. Petcrsen, and J. T. Rosenberg, Shock compression of feldspars, J. Geophys. Res., 74, 2727-2746, $1969 b$.

Ahrens T. J., T. Takahashi, and G. Davies, A proposed equation of state of stishovite, J. Geophys. Res., 75, 310-316, 1970.

Al'tshuler, L. V., L. M. Kuleshova, and M. N. Pavlovskii, The dynamic compressibility, equation of state, and electrical conductivity of sodium chloride at high pressures, Sov. Phys. JETP, 12, 10-15, 1961 .

Anderson, Don L., A seismic equation of state, Geophys. J., 13, 9, 1967.

Anderson, D. L., Bulk modulus systematics, J. Geophys. Res., $74,3857-3864,1969$.

Anderson, Don L., and H. Kanamori, Shock-wave equations of state for rocks and minerals, J. Geophys. Res., 20, $6477-6502,1968$

Anderson, O. L., Some remarks on the volume dependence of the Grüneisen parameter, J. Geophys. Res., 73, 5187-5194, 1968.

Anderson, O. L., and P. Andreatch, Pressure derivatives of elastic constants of single crystal magnesium oxide at $23^{\circ}$ and $-195.8^{\circ} \mathrm{C}$, J. Amer. Ceram. Soc., 49, 404-409, 1966.

Bassett, W. A., and J. D. Barnett, Isothermal compression of stishovite and coesite up to 85 kbars at room temperature by X-ray diffraction, Phys. Earth Planet. Interiors, 3, 54-60, 1970.

Bassett, W. A., Taro Takahashi, and P. W. Stook, X-ray diffraction and optical observations on crystalline solids up to 300 kbars, Rev. Sci. Instrum, 38, 37-42, 1967.

Bassett, W. A., T. Takahashi, H. K. Mao, and J. S. Weaver, Pressure-induced phase transformation in $\mathrm{NaCl}, J$. Appl. Phys. 39, 319-325, 1968.

Barnett, J. D., and H. T. Hall, High pressure-high temperature, X-ray diffraction apparatus, Rev. Sci. Instr., 35, 175-182, 1964.

Barnett, J. D., J. Pack, and H. T. Tall, Structure determination of a ferroelectric phase of sodium nitrate above $45 \mathrm{kbar}$, Proc. Amer. Crystal Ass., 5, 102-131, 1969.

Barsch, G. R., and Z. P. Chang, Adiabatic, isothermal, and intermediate pressure derivatives of the elastic constants for cubic symmetry, 2, Numerical results for 25 materials, Phys. Status Solidi, 19, 139-151, 1967.

Birch, F., The velocity of compressional waves in rocks to 10 kbars, 2, J. Geophys. Res., 66, 2199-2224, 1961.

Birch, F., Density and composition of the mantle and core, $J$. Geophys. Res., 69, 4377, 1964.

Brace, W. F., Some new measurements of linear compressibility of rocks, J. Geophys. Res., 70, 391-398, 1965.
Brace, W. F., C. H. Scholz, and P. N. LaMori, Isothermal compressibility of kyanite, andalusite and sillimanite from synthetic aggregates, J. Geophys. Res., 74, 2089-2097, 1969.

Bridgman, P. W., The compression of forty-six substances to $50,000 \mathrm{~kg} / \mathrm{cm}^{2}$, Proc. Amer. Acad. Arts Sci., 74, 21-51, 1940.

Bridgman, P. W., The compression of twenty-one halogen compounds and eleven other simple substances to 100,000 $\mathrm{kg} / \mathrm{cm}^{2}$, Proc. Amer. Acad. Arts Sci., 76, 1-24, 1945.

Bridgman, P. W., Linear compressions to $30,000 \mathrm{~kg} / \mathrm{cm}^{2}$ including relatively incompressible substances, Proc. Amer. Acad. Arts Sci., 77, 187-234, 1949.

Carter, W. J., S. P. Marsh, J. N. Fritz, and R. G. McQueen, The equation of state of selected materials for high pressure references, in Proceedings of Symposium on Accurate Characterization of the High Pressure Environments, edited by E. Lloyd, National Bureau of Standards, Gaithersburg, Md., 1968.

Christian, R. H., The equation of state of alkali halides at high pressure, Univ. Calif. Radiation Lab. Rep. 4900, 1-89, 1957.

Clendenen, R. L., and H. G. Drickamer, Effect of high pressure on the compressibilities of five alloys, J. Chem. Phys., 44, 4385-4386, 1966a.

Clendenen, R. L., and H. G. Drickamer, Lattice parameters of nine oxides and sulfides as a function of pressure, $J$. Chem. Phys., 44, 4223-4228, $1966 \mathrm{~b}$.

Decker, D. L., Equation of state of $\mathrm{NaCl}$ and its use as a pressure gauge in high-pressure research, J. Appl. Phys., 36, 157-161, 1965.

Decker, D. L., Equation of state of sodium chloride, J. Appl. Phys., 37, 5012-5014, 1966.

Decker, D. L., W. A. Bassett, L. Merrill, H. T. Hall, and J. D. Barnett, High pressure calibration, a critical review, High Pressure Data Center, Brigham Young University, Provo, Utah, pp. $163,1969$.

Drickamer, H. G., R. W. Lynch, R. L. Clendenen, and E. A. Perez-Albuerne, $\mathrm{X}$-ray diffraction studies of the lattice parameters of solids under very high pressure, Solid State Physics, 19, 135-228, 1966.

Fowles, G. R., G. E. Duvall, J. Asay, P. Bellamy, F. Fleistman, D. Grady, T. Michaels, and R. Mitchell, Gas gun for impact studies, Rev. Sci. Instrum, 41, 984-996, 1970.

Freud, P. J., and P. N. Lamori, Non-dispersive high pressurehigh temperature X-ray diffraction analysis, Proc. Amer. Crystal Ass., 5, 155-162, 1969.

Freud, P. J., and C. B. Sclar, Apparatus for high-pressure high-temperature X-ray powder diffraction studies, Rev. Sci. Instrum, 40, 434-437, 1969.

Fritz, J. N., S. P. Marsh, W. J. Carter, and R. G. McQueen, The Hugoniot equation of sodium chloride in the sodium chloride structure, in Proceeding of Symposium on Accurate Characterization of High Pressure Environment, edited by E. Lloyd, National Bureau of Standards, Gaithersburg, Md., 1968.

Fritz, J. N., S. P. Marsh, W. J. Carter, and R. G. McQueen, The Hugoniot equation of state of sodium chloride in the sodium chloride structure, Los Alamos Sci. Lab. Rep. LA-De-9989, 1969.

Graham, R. A., Impact techniques for the study of physical properties of solids and shock-wave loading, Trans. ASME, J. Basic Eng., 911-918, Dec. 1967.

Grover, R., Comments on the comparison of dynamic and static compression data, J. Phys. Chem. Solids, 31, 2347-2352, 1970.

Hart, H. V., and H. G. Drickamer, Effect of high pressure on the lattice parameters of $\mathrm{Al}_{2} \mathrm{O}_{3}, J$. Chem. Phys., 43, 2265-2268, 1965.

Hauver, G. E., and A. Melani, Shock Hugoniot of single crystal NaCl, Ballistics Res. Lab. Mem. Rep. 2061, 27 pp., 1970.

Haygarth, J. C., I. C. Getting, and G. C. Kennedy, Determination of the pressure of the Barium I-II transition with single-stage piston-cylinder apparatus, J. Appl. Phys., 38, 4557-4564, 1967.

Haygarth, J. C., H. D. Ludemann, I. C. Getting, and G. C. Kennedy, Determination of portions of the Bismuth III-V and IV-V equilibrium boundaries in single-stage piston-cylinder 
apparatus, in Proceedings of Symposium on Accurate Characterization of the High Pressure Environment, edited by $\mathrm{E}$. Lloyd, National Bureau of Standards, Gaithersburg, Md., 1968.

Heydemann, P. L. M., The Bi-I-II transition pressure measured with a dead weight piston gauge, J. Appl. Phys., 38, $2640-2644,1967$.

Jamieson, J. C., Structural transitions in solids at high pressures, in Physics of Solids at High Pressures, edited by C. T. Tomizuka and R. M. Emrick, 444-459, Academic, New York, 1965.

Jamieson, J. C., and B. Olinger, Pressure inhomogeneity, a possible source of error in using internal standards for pressure gages, in Proceedings of Symposium on Accurate Characterization of High Pressure Environments, E. Lloyd editor, National Bureau of Standards, Gaithersburg, Md., 1968a.

Jamieson, J. C., and B. Olinger, High-pressure polymorphism of titanium dioxide, Science, 161, 893-895, 1968b.

Jeffery, R. N., J. D. Barnett, H. B. Vanfleet, and H. T. Hall, Pressure calibration to $100 \mathrm{kbars}$ based on the compression of NaCl, J. Appl. Phys., 37, 3172-3180, 1966.

Jones, A. H., and N. H. Froula, Uniaxial strain behavior of four geological materials to $50 \mathrm{kbars,} \mathrm{General} \mathrm{Motors} \mathrm{Materials} \mathrm{and.}$ Structures Lab. Rep. MSL-68-19, March 1969.

Jones, A. H., W. M. Isbell, and C. J. Maiden, Measurement of the very-high pressure properties of materials using a light gas gun, J. Appl. Phys., 37, 3493, 1966.

Jones, A. A., W. M. Isbell, F. H. Shipman, R. D. Perkins, S. J. Green, and C. J. Maiden, Material property measurements for selected materials, in General Motors Materials and Structures Lab. Rep. NAS2-3427, 1968.

Kennedy, G. C., and P. N. Lamori, The pressures of some solid-solid transitions, J. Geophys. Res., 67, 851-856, 1962.

Knopoff, L., and J. N. Shapiro, Comments on the interrelationships between Grüneisens parameter and shock and isothermal equations of state, J. Geophys. Res., 74, 1439-1450, 1969.

LaMori, P. N., Compressibility of rocks and minerals to $450^{\circ} \mathrm{C}$ and $36 \mathrm{~kb}$ and their applications to the upper mantle, $\mathrm{Ph} . \mathrm{D}$. thesis, Northwestern University, Chicago, I1l., pp. 205, 1967.

Lewis, G. K., and H. G. Drickamer, Effect of high pressure on the lattice parameter of $\mathrm{Cr}_{2} \mathrm{O}_{3}$ and $\alpha \mathrm{Fe}_{2} \mathrm{O}_{3}, J$. Chem. Phys., $45,224-226,1966$.

Linde, R. K., and P. S. DeCarli, Polymorphic behavior of titania under dynamic loading, $J$. Chem. Phys., 50, 319-325, 1969.

Linde, R. K., and D. N. Schmidt, Measuring the submicrosecond response of shock loaded materials, Rev. Sci. Instrum., 37 $1-7,1966$

Liu, L. G., T. Takahashi, and W. A. Bassett, Compression of stishovite and magnesian ilmenite at $25^{\circ} \mathrm{C}$ (abstract), EOS, Trans. Amer. Geophys. Union, 50, 312, 1969.

Lloyd, E., C. W. Beckett, and F. R. Boyd, Measurements in the high pressure environments, Science, 164, 860-862, 1969.

Lower, J. H., and T. J. Ahrens, Shock compression experiments with a high performance propellant gun, Bull. Amer. Phys., Sec. II, 14, 1163, 1969.

Lynch, R. W., and H. G. Drickamer, Effect of high pressure on the lattice parameters of diamond, graphite and hexagonal boron nitride, J. Chem. Phys., 44, 181-184, 1966.

Lysne, P. C., A comparison of calculated and measured low-stress Hugoniots and release adiabats of dry and watersaturated tuff, J. Geophys. Res., 75, 4375-4386, 1970.

McQueen, R. G., J. N. Fritz, and S. P. Marsh, On the equation of state of stishovite, J. Geophys. Res., 68, 2319-2322, 1963.

McQueen, R. G., and H. M. Marsh, Compressibility; elastic constants in Handbook of Physical Constants, edited by S. P. Clark, Jr., Memoir 97, Geological Society of America, 1966.

McQueen, R. G., J. C. Jamieson, and S. P. Marsh, Shock-wave compression and X-ray studies of titanium dioxide, Science. $155,1401-1404,1967 a$.

McQueen, R. G., S. P. Marsh, and J. N. Fritz, Hugoniot equation of state of twelve rocks, J. Geophys. Res., 72, 4999, $1967 \mathrm{~b}$.

McQueen, R. G., S. P. Marsh, J. W. Taylor, J. N. Fritz, and W. J. Carter, The equation of state of solids from shock wave studies, in High Velocity Impact Phenomena, edited by R. Winslow, Academic, New York, 1970.
McWhan, D. B., Linear compression of $\alpha$ quartz to $150 \mathrm{kbar}, J$. Appl. Phys., 38, 347-352, 1967.

McWhan, D. B., Symposium on Crystal Structure at High Pressure, vol. 5, Trans. Amer. Crystal. Ass., edited by D. B. McWhan, 161 pp., 1969.

McWhan, D. B., and W. L. Bond, Simple high pressure X-ray powder camera, Rev. Sci. Instrum., 35, 626-627, 1964.

Mao, H. K., W. A. Bassett, and T. Takahashi, Effect of pressure on crystal structure and lattice parameters of iron up to 300 kbar, J. Appl. Phys., 38, 272-276, 1967.

Mao, H. K., T. Takahashi, W. A. Bassett, J. S. Weaver, and S. Akimoto, Effect of pressure and temperature on the molar volumes of wüstite and of three $\left(\mathrm{Fe}, \mathrm{Mg}_{2} \mathrm{SiO}_{4}\right.$ spinel solid solutions, J. Geophys. Res., 74, 1061-1069, 1969.

Mao, H. K., Taro Takahashi, and W. A. Bassett, Isothermal compression of the spinel phase of $\mathrm{Ni}_{2} \mathrm{SiO}_{4}$ up to $300 \mathrm{~kb}$ at room temperature, Phys. Earth Planet. Interiors, 3, 51-53, $1970 a$

Mao, N., J. Ito, J. F. Hays, J. Drake, and F. Birch, Composition and elastic constants of hortonolite dunite, J. Geophys. Res. $75,4071-4076,1970 b$.

Mizutani, H., Y. Hamano, Y. Ida, and S. Akimoto, Compressional-wave velocities of fayalite, $\mathrm{Fe}_{2} \mathrm{SiO}_{4}$ spinel, and coesite, J. Geophys. Res., 75, 2741-2747, 1970.

Morgan, J. A., Equation of state measurement techniques for the LASL light-gas gun, Bull. Amer. Phys. Soc. 2, 14, 1163, 1969.

Pastine, D. J., and J. W. Forbes, Accurate relations determining the volume dependence of the quasi-harmonic Grüneisen parameter, Phys. Rev. Lett., 21, 1582-1585, 1968.

Perez-Albuerne, E. A., and H. G. Drickamer, Effect of high pressures on the compressibilities of seven crystals having $\mathrm{NaCl}$ and $\mathrm{CsCl}$ structure, J. Chem. Phys., 43, 1381-1387, 1965.

Perez-Albuerne, E. A., K. F. Forsgren and H. G. Drickamer, Apparatus for $\mathrm{X}$-ray measurements at very high pressure, Rev. Sci. Instrum 35, 29-33, 1964.

Petersen, C. F., W. J. Murri, M. Cowperthwaite, Hugoniot and release-adiabat measurements for selected geologic materials, $J$. Geophys. Res., 15, 2063-2072, 1970.

Rice, M. H., R. G. McQueen and J. M. Walsh, Compression of solids by strong shock waves, in Solid State Physics, vol. 6 , edited by F. Seitz and D. Turnbull, pp. 1-63, Academic, New York, 1958 .

Schreiber, E., O. L. Anderson, N. Soga, N. Warren, and C. Scholz, Sound velocity and compressibility for lunar rocks 17 and 46 and for glass spheres from the lunar soil, Science, 167 732-734, 1970.

Shipman, F. H., W. M. Isbell, and A. H. Jones, High pressure Hugoniot measurements on several Nevada Test Site rocks, General Motors Materials and Structures Lab. Rep. MSL-68-15, March 1969.

Silbermann, M. L., Isothermal compression of two iron-silicon alloys to $290 \mathrm{kbars}$ at $23^{\circ} \mathrm{C}$, M.S. Thesis, University of Rochester, Rochester, N. Y., 72 pp., 1967.

Spetzler, H., Equation of state of polycrystalline and singlecrystal $\mathrm{MgO}$ to $8 \mathrm{kbars}$ and $800^{\circ} \mathrm{K}, J$. Geophys. Res., 75 , 2073-2087, 1970 .

Stephens, D. R., and E. M. Lilley, Static $P \cdot V$ curves of cracked and consolidated earth materials to 40 kilobars, in Shock Metamorphism of Natural Materials, edited by B. M. French and N. M. Short, pp. 51-57, Mono, Baltimore, Md., 1968.

Stephens, D. R., and E. M. Lilley, Compressibilities of lunar crystalline rock, microbreccia and fines to 40 kilobars, Science, 167, $731-732,1970$.

Takahashi, T., and L. G. Liu, Compression of ferromagnesian garnets and the effect of solid solutions on the bulk modulus, J. Geophys. Res., 75, 5757-5766, 1970.

Takahashi, T., W. A. Bassett, and H. K. Mao, Isothermal compression of the alloys of iron up to 300 kilobars at room temperature: Iron-nickel alloys, J. Geophys. Res., 73, 4717-4725, 1968

Thomsen, L., On the fourth-ordes anharmonic equation of state of solids, J. Phys. Chem. Solids, 31, 2003-2016, 1970.

Vaidya, S. N., and G. C. Kennedy, Compressibility of 18 metals to 45 kbar, J. Phys. Chem. Solids, 3I, 2329-2346, 1970. 
Wang, C. Y., Phase transitions in rocks under shock compression, Earth Planet. Sci. Lett. 2, 107-113, 1967.

Wang, C. Y., Constitution of the lower mantle as evidence from shock wave data for some rocks, J. Geophys. Res., 73, 6459-6476, 1968a.

Wang, C. Y., Equation of state of periclase and Birch's relationship between velocity and density, Nature, 218, 74, $1968 b$.
Weaver, J. S., Taro Takahashi, and W. A. Bassett, Calculation of the $P$-V relation for the B1 phase of $\mathrm{NaCl}$ up to 300 kilobars at $25^{\circ} \mathrm{C}$, in Proceedings of Symposium on Accurate Characteri. zation of High Pressure Environments, edited by E. Lloyd, National Bureau of Standards, Gaithersburg, Md., 1968.

Weir, C. E., G. J. Piermarini, and S. Block, Instrumentation for single crystal X-ray diffraction at high pressures, Rev. Sci. Instrum. 40, 1133-1136, 1969.

\section{Melting Relations}

\section{Peter J. Wyllie}

The process of magma generation with subsequent uprise and intrusion or extrusion of magma is one of the fundamental processes in the evolution of the earth. Rheological and other physical properties change markedly wherever and whenever partial melting occurs. The melting relations of minerals and rocks can now be measured in the laboratory to pressures corresponding to depths of more than $250 \mathrm{~km}$. The measurements provide limits for temperatures within the earth and a basis for extrapolation to greater depths. This report outlines experimental results for the melting of elements, minerals, and rocks under various conditions, in a dry state or in the presence of water and other volatile components. There is overlap with reports on experimental petrology in another section, but it is reduced to a minimum by limiting this review to melting curves and properties, without attention to the more detailed aspects of petrogenesis.

Luedemann and Kennedy [1968] measured the melting curves of lithium, sodium, potassium, and rubidium to $80-\mathrm{kb}$ pressure. At about $60 \mathrm{~kb}$ they found rather sharp changes in the slope of the melting curves for lithium, potassium, and rubidium that could represent maximums in fusion curves analogous to the maximum previously discovered for cesium. The relationship between the temperature of melting for a given pressure and the compression measured at room temperature was discussed by Luedemann and Kennedy and Kennedy and Vaidya [1970]. The linear relationship for metals breaks down at pressures where maximums occur on the fusion curves. Gilbert [1969] found that the linear relationship does not appear to hold for silicate minerals. Kennedy and Vaidya proposed a re-evaluation of the various equations used to describe the effects of pressure on fusion temperatures. Extrapolation of melting curves for silicates or metals for estimation of melting temperatures in the deep mantle and core remains uncertain.

Between 1958 and 1964 the availability of the piston-cylinder apparatus had yielded melting curves to mantle pressures for a number of silicate minerals: albite, diopside, fayalite, forsterite, jadeite, and pyrope. Additional fusion curves for individual minerals and for

Peter J. Wyllie is with the Department of Geophysical Sciences, University of Chicago, Chicago, Illinois 60637. mineral assemblages have since been reported. The fusion curve for fayalite was measured to $40 \mathrm{~kb}$ by $\mathrm{Hsu}$ [1967] and extended to higher pressures above the olivine-spinel transition by A kimoto and Komada [1967]. Gilbert [1969] presented a melting curve for acmite to $45 \mathrm{~kb}$. Using a differential thermal analysis technique with tungsten/rhenium thermocouples, Williams and Kennedy [1969] redetermined the melting curve of diopside, to $50-\mathrm{kb}$ pressure. They claimed considerable improvement over existing methods employing quench techniques and platinum-rhodium thermocouples. Lindsley [1966, 1967] described melting relationships for sanidine and parts of the system $\mathrm{KAlSiO}_{4}-\mathrm{SiO}_{2}$ to 40 kb. Bell and Roseboom [1969] presented data for albite and jadeite and derived all theoretically possible types of $P-T \cdot X$ diagrams for melting at high pressures with four solid phases of different compositions (jadeite, albite, quartz, and nepheline) in a binary system ( $\mathrm{NaAl}$ $\mathrm{SiO}_{4}-\mathrm{SiO}_{2}$ ). Luth [1969] presented the eutectic melting relationships for $\mathrm{NaAlSi}{ }_{3} \mathrm{O}_{8}-\mathrm{SiO}_{2}$ and $\mathrm{KAlSi}{ }_{3} \mathrm{O}_{8}-\mathrm{SiO}_{2}$ to $20 \mathrm{~kb}$ and found that the composition of the eutectic liquid was enriched in the feldspar component with increasing pressure. Bell and Davis [1969] described melting relationships in the system jadeite-diopside at 30 and $40 \mathrm{~kb}$.

More complex silicate systems have been studied. Kushiro [1968] studied liquid compositions in a series of systems $\mathrm{Mg}_{2} \mathrm{SiO}_{4}-\mathrm{SiO}_{2}-X$, where $X$ represents $\mathrm{CaMgSiO}_{4}, \mathrm{CaAl}_{2} \mathrm{O}_{4}, \mathrm{NaAlSiO}_{4}$, and $\mathrm{MgAl}_{2} \mathrm{O}_{4}$. His results in the pressure range 7 to $40 \mathrm{~kb}$ were applied to the problem of the compositions of magmas formed at various depths by partial fusion of mantle peridotite. He described also the phase relationships in the system $\mathrm{Mg}_{2} \mathrm{SiO}_{4}-\mathrm{CaMgSi} \mathrm{O}_{6}-\mathrm{SiO}_{2}$ at $20 \mathrm{~kb}$ [Kushiro, 1969]. O'Hara and Yoder [1967] reviewed the formation and fractionation of basic magmas at high pressures by using results at $30 \mathrm{~kb}$ on the join $\mathrm{CaMgSi}_{2} \mathrm{O}_{6}-\mathrm{Mg}_{3} \mathrm{Al}_{2} \mathrm{Si}_{3} \mathrm{O}_{12}$ and adjacent parts of the plane $\mathrm{CaSiO}_{3}-\mathrm{MgSiO}_{3}-\mathrm{Al}_{2} \mathrm{O}_{3}$ and similar compositions obtained by mixing natural minerals separated from a garnet-peridotite nodule from a kimberlite. The effect of pressure on the system $\mathrm{MgO}-\mathrm{SiO}_{2}-\mathrm{TiO}_{2}$ was determined by MacGregor [1969]. Liquids became progressively richer in $\mathrm{TiO}_{2}$ as pressure increased to $40 \mathrm{~kb}$. The melting relationships to $20 \mathrm{~kb}$ for the composition $\left(\mathrm{An}_{70} \mathrm{Ab}_{30}\right)_{3} \mathrm{Fo}_{1}$ were determined by Emslie and Lindsley [1969], as a guide to anorthosite genesis.

Presnall [1969] presented a detailed geometrical analysis of partial fusion by using simple systems as examples. 